\title{
FLASHOVER ON H.V. INSULATORS COATED WITH A NON-LINEAR CONDUCTIVE FILM
}

\author{
BY \\ MOHAMED IZZULARAB \\ Faculty of Engg. A Tech. \\ Menoufia University, \\ Shebin E1-Kom ECYPT.
}

\section{ABSTRACT}

himing to improving the insulator resistance in the polluted media, a aew proposed model consisting of an insulating surface coated by a non-1inear conductive film has been studied.

There are kwo important roles of the non-linear filn. At low voltage gradient, a very small current passes. This low leakage curzent tends to raise the surface temperatures slightly above the ambient and retards dew deposition, which contributes to many flashovers. At high voltage gradient, i.e. the condition of dry zones formation; the leakage current increases sharpiy under the discharge across the dry zones, so this discharge diminishes.

To investigate the effect of this non-linear film on the surface discharge and flashover, the electrical characteristics of non-linear film has been studied, and both theoretical model and experimental work, which has been carried out with simple model are discussed.

It has been found that the chance of the formation of Local surface discharges decreases, and the critical Elashover voltage has increased due to the existence of this non linear film. The nathematical experessions of the electric field in the discharge colum and pollution layer were deduced for computing the critical flashover voltage.

\section{IMTRODUCTION}

The main way to improve the behavior of B.V.polluted insuzstors is to increass their leakage length. The other way is to coat tha insulazor sulface by linear conductive film such as the type of semi-conductive glass insulator.

The insulators which are coated by linear conductive films had been studied in both aspects: in real insulator /1/ for measuring the flashover voltage; and by physlcal-experinental 
Laboratory models / $/ 2 /$ to understand the flashover mechanism and investigate the different criteria for calculating the critical flashover voltage.

Owing to the lirear conducting film; a continuous leakage current flows. It has been found that 11,21 this leakage curront raises the surface temperature slightly above the ambient and retards dew deposition. Besides; the linear film uniformely distributes the electric field on the insulator surface, which increases the value of Elasnover voltage. So these two tmportant effects contribute to many flashovers.

The linear film is normally designed with high resistance tp avold the bad effect of high leakage current, which should be within a maximum of $1 \pi \mathrm{A}$. In such type of insulators $/ 1 /$. This value is high enough to contribute to flashover, specially if the surface discharge has already been formed. In addition, this value of leakage current causes an increase in losses w2thout: benifits in normal condition.

The ain of this present work is to investigate and study the behaviour of H.V. Insulator coated with non-linear conductive Eilm. The non-linear film gives very small leakage curront in low electric field, so it decreases the losses in nomal operation conditions. In the cases of high electric field zones formation: the non-linear film gives very high surface current, which aviods the surface discharge and iashover.

Ii. ELECTRICAL CHARACTERISTICS OF NON-LINEAR MATERIALS

In general; the current-voltage characterlstics of semi conductive materials such as silicon or zinc oxyce can be represented by $/ 3,4 /$ the following equation:

where,

$$
\left.I_{s}=a v_{s}^{b} \quad \ldots \quad \ldots \quad \ldots, \ldots 11\right)
$$

a \& $b$ are parameters of current-voltage equation.

Figure (1) shows the current-voltage characteristics which nay be divided into three zones depending on the value of $b$. In the first zone; the value of $b$ is equal to one and then the characteristic is linear. The value of b in the second zone equais two; and in the third zone this value is greater than two, and may reach 30 or greacer than 30 depending on the type of semil conductive material used.

A simple experimental test has been set up for measuring the I-V characseristics for different lengths of a substrate of zinc oxide 97 is with Eive oxide additions. These are: $E_{12} 0_{3} 0.5$ s $\mathrm{Mn} \mathrm{O} 20.5 i, \mathrm{C}_{3} \mathrm{O}_{4} 0.58, \mathrm{C}_{2} \mathrm{O}_{3} 0.58$, and $\mathrm{Sb}_{2} \mathrm{O}_{3} 13$. This rixture is used $/ 3 /$ normaly in the fabrication of the Lighting arzest disks. The specimen has been tested usang the total length h c:: $3 / 4 \mathrm{~h} ;$ in; and $1 / 4 \mathrm{~h}$.

In the test, the voltage has been increased gradually and the current was measured. At che end of the test, the specimen was cested anotrer time for the total length h beginning with high vaive of voltage and decreasing it gradualiy.

The h.v. source is a rectified voltage from $0-40 \mathrm{kv}$; with zaximan zurtert o? 10 MA. model ABK-45 ZANID. The specimen was 
$33 \mathrm{~mm}$ long; $4.5 \mathrm{~mm}$ wide; and $2 \mathrm{~mm}$ thick.

Figure (2) shows the experimental results for differenc values of length h. It has been found that, after the specimon passes the value of a threshold voltage $V_{S s}$; the I(v) characteristics with the length h(line a) can be represented by:

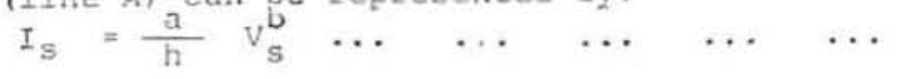

The characteristics, before $V_{\text {ss }}$ were not regular i.e the value of Is for length equal to $3 / 4 \mathrm{~h}$ is greater than $f$ h (1ine B). This non regularity may be caused $/ 3 /$ by thermal effects in the specimen which strongly affect conductivity. Also when the experiment was performed starting with the highest voltage value and decreasing it gradually, the characteristics obtained did not coincice with the characteristics of the first experiment for the same specimen. This may be aiso due to the thermal effect in another form. As we started with the high value, the heat content was formed early in the specimen.

The following form may be used for computing the potential gradient in the specimen:

$$
E_{s}=\frac{3}{\partial n}\left[\frac{I_{s}}{a}\right)^{b} \quad \ldots \quad \ldots, \quad \ldots, \quad \ldots
$$

This equation must be calculated numerically at each point on the surface of the specimen.

\section{POLLUTION LAYER ON THE MON LINEAR FILM}

In the flashover test $/ 5,6 /$, the pollution layer has been presented by a solution of Nacl which has a linear characteristic of its resistance. So if a pollution layer has deposited on an insulator surface which is coated with a non-linear film, the characteristics of the two layers together will normally depend on the value of the applied voltage. Two cases of the applied voltage are illustrated in Figure (3). The applied voltage is greater or lower than the threshold voltage $V_{s s}$ of the non-linear filin.

When the applied voltage value is lower than the threshold voltage $V_{S S}$ of non linear film; the characteristic of non-linear filn is linear. Therefore, the total resistance of the two layers together is the parallel resultant of the two layer resistances. Because the resistance of non-linear film is too highly greater than the resistance of pollution layer; the resistance of the two layers together is equal to the resistance of pollution layer alone.

The second case when the applied voltage is greater than the threshold voltage was not considered in this study. This is because the applied voltage must be lower than the threshold voltage in normal condition to avoid the high leakage current. However on a certain zone of insulator surface, which have a very high pollution resistance or dry zone; the characteristic of non linear film has the only role without considering the pollution. layer. 
E. 40 M. 12ZU1. $\triangle \mathrm{KAB}$

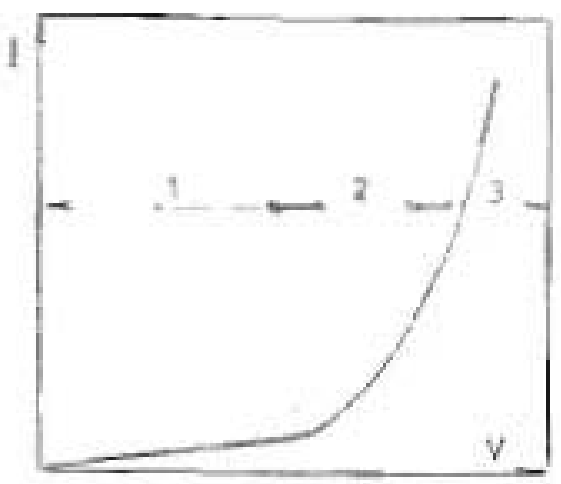

Pig. I1):Characterintis of current-voltago.

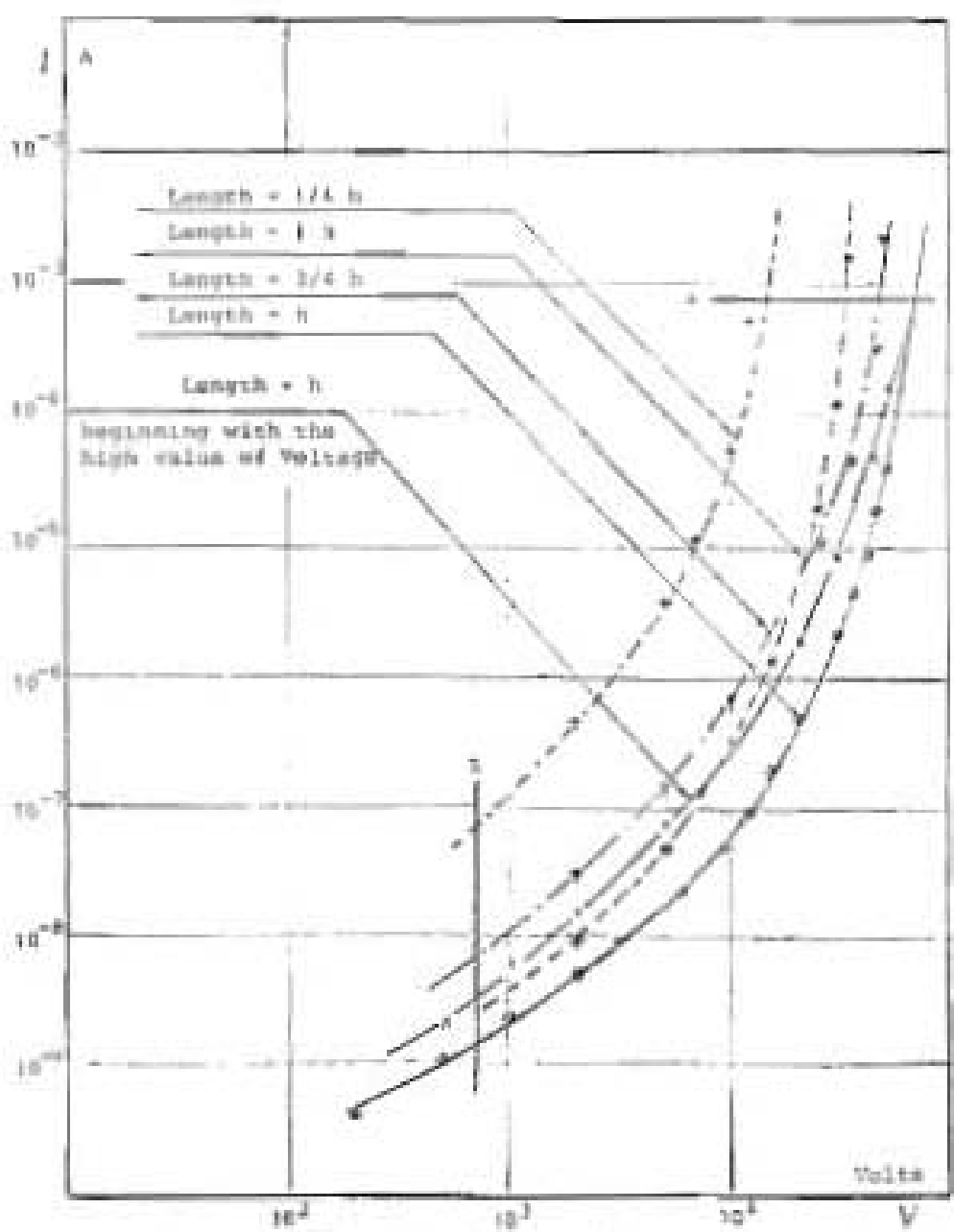

F1F, (2): Experisental results of I-V. 
IV. ROLE OF NON-LINEAR FILM ON THE INSULATOR IN OPERATION:

There are two important roles of the non linear film, which costs the insulator surface. The first role affects at normal operation of insulator where the leakage current tends to raise the curface temperature slightly above the anbient and retards dow doposition, which contributes to many flarhovers.

The orkez role dominates when a dry zone $1 \mathrm{~s}$ formed and the discharge grows across it. The high gradient which formed this discharge increases also sharply the leakage current in this portion of the non inear fila because the applied voltage at thit zone will bo greater than the threshold voltage at the moment af growth, so this discharga will diminish. This is so, because the hich leakage current in the non linear filin under the discharge affec* ts tho electric field in the discharge column; and the current necessary for the discharge.

\section{FLASHOVER VOLTAGE CALCULATION}

Flashover voltage calculation $/ 2,7,8,8$, depends on the calculation of electric fleld on the discharge column and the pollution layer which is in series with the discharge; and also the current path under the discharge in the nonlinear fllm which affects the electric field in the discharge.

Because of non-1inearities in the electrical equation; the electric field calculation is very difficult; so the numerical computation such as finite element or finite differonce can be used for solving the electric field problet in such cases.

The following equations have been deduced for the differenc necessary relation for solving this problem:

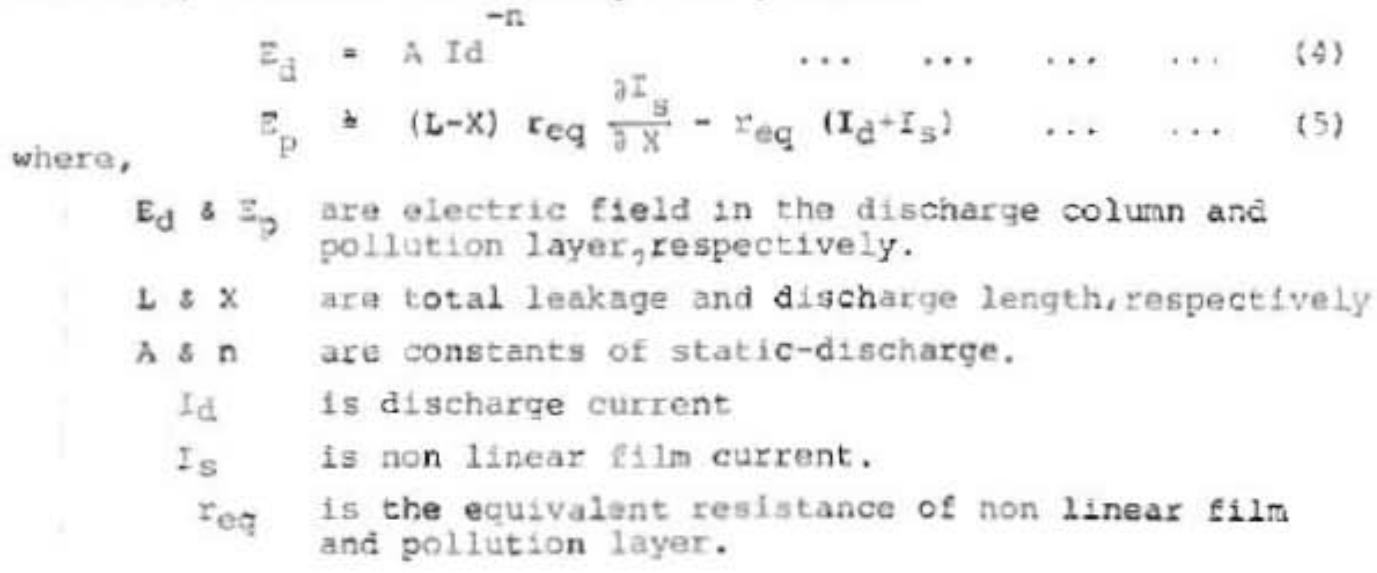

The discharge current. If can be calculated by using the transition characterintic of discharge in gases between glow ard arc.

The ourrent in non linear film Is can be calculated where the voltage across the discharge is equal to the voltage acrosi the dry portion of the not linear film as shown in Fig. (4). So the current $I_{s}$ can be calculated as follows: 


$$
I_{e}=a+\frac{A \times I_{d}^{-n}+v_{B}}{h} \mid \ldots \ldots \ldots
$$

where,

$$
\begin{aligned}
& v_{1}=\text { total electrodes voltage drop. } \\
& \text { s = the length of non IInear HLa witch cepresents the } \\
& \text { dity zone. }
\end{aligned}
$$

\section{RESUL.TS AND DISCUSSIONS}

The formation of llashover bequns by a local discharge acroas a dry zone on tre tnaulator surface, and after blast the discharte propagater co include a1L tha leakaga path on the insulator murtsce between the high voltage and aarthed eloctrodes. This propagation of discharge in teatridted by the oritieal values of current and voltage $/ 5,6 /$.

To 11lustratin tha etfoct of the non linear itin coatisig the insulator surface on the flashover, the following results deal with the effeot of non limear filn on the firmt itage of the flashover whare a local discharge s focmed eorelis the dry zone.

It Stqure (5), the electrical characteriotios I-V hate beuth presuntod for three spucimens of atne oxide coating the surfact of cernsic plates as shown in Fiqure $(6)$. This thas adterlitid

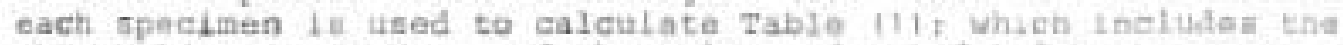
threshold voltage $\mathrm{V}_{\mathrm{ma}}$, and the values of $\mathrm{a}$ and $\mathrm{b}$ tor the spertan. The curva of $t-V$ has been divided into three aones and hence.

\begin{tabular}{|c|c|c|c|c|c|c|c|c|c|}
\hline \multirow{2}{*}{$\begin{array}{c}\text { Speciaen } \\
\text { to. }\end{array}$} & \multirow{2}{*}{ Length } & \multirow{2}{*}{$\begin{array}{l}\text { Widel } \\
\text { ch }\end{array}$} & \multicolumn{3}{|c|}{ a } & \multicolumn{3}{|c|}{$b$} & \multirow{2}{*}{$\frac{V_{ \pm 2}}{i x}$} \\
\hline & & & $a_{1}$ & $a_{2}$ & $a_{3}$ & $b_{4}$ & $b_{2}$ & $b_{3}$ & \\
\hline$t$ & 6.5 & 2 & $2.57 \times 10^{-10}$ & $2.04 \times 10^{-14}$ & $5.13 \times 10^{-56}$ & 1.2 & 2,3 & $|17,8|$ & II \\
\hline 1 & 8 & 2 & $4.0 \times 10^{12}$ & $2.6 \times 10^{-17}$ & $2,43 a 10^{52}$ & .07 & 2,6 & 13,6 & 20 \\
\hline 3 & a & 2 & $2,79 \times 10^{-13}$ & 8. $24 \times 10^{19}$ & $2.1 \times 10^{-56}$ & 9.63 & 1.25 & 15.0 & 26 \\
\hline
\end{tabular}
the values of a i b have been calculated for each aone. Bo, that values of $a$ and b sre given by $a_{1}, a_{2}, a_{3}, b_{1}, b_{2}, b_{2}$.

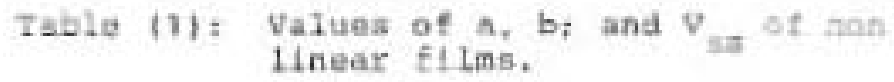

It was observed that the apecimen 2 has the same length and with as specimen 3 ; but the results of $a, b$, and $V_{s}$ are not iduntical for each specinen. This contradiction may be due to the availabie technique for preparing the wpecimens. This cechinique used the pover of zinc oxide and alxad it with water or mloohal. The nixeura is deposited on the surface of ceramic plates. The specitient are dried in an oven. Thin technique is good technlquo but gives the film without control of thickness, and bonce the difference between the two specimens. 


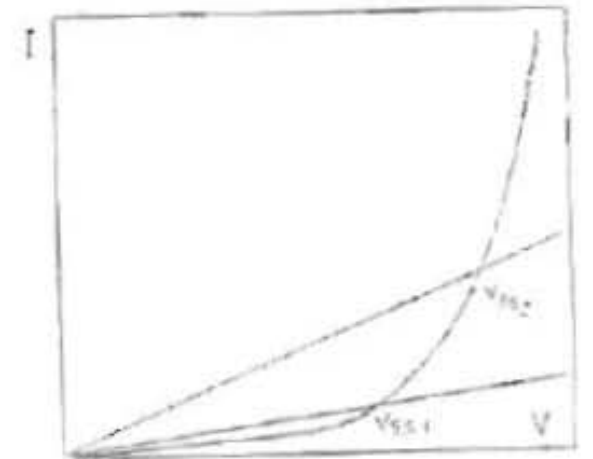

Fig. (3): 1-V characteristios of pollution layor and non linear film.

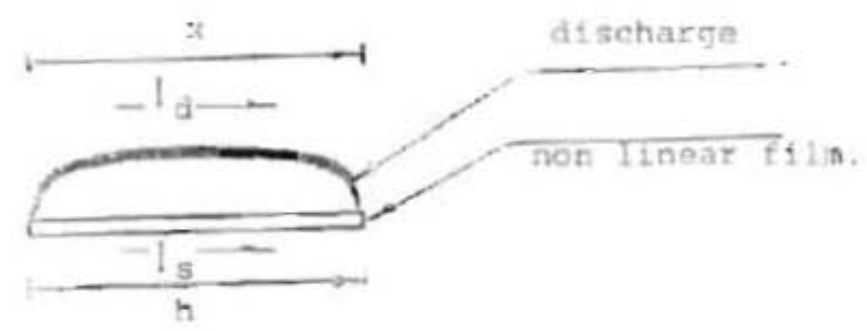

Fig. $(4)$ : Electrical moded. 
E. 44

M. IZZULARAB

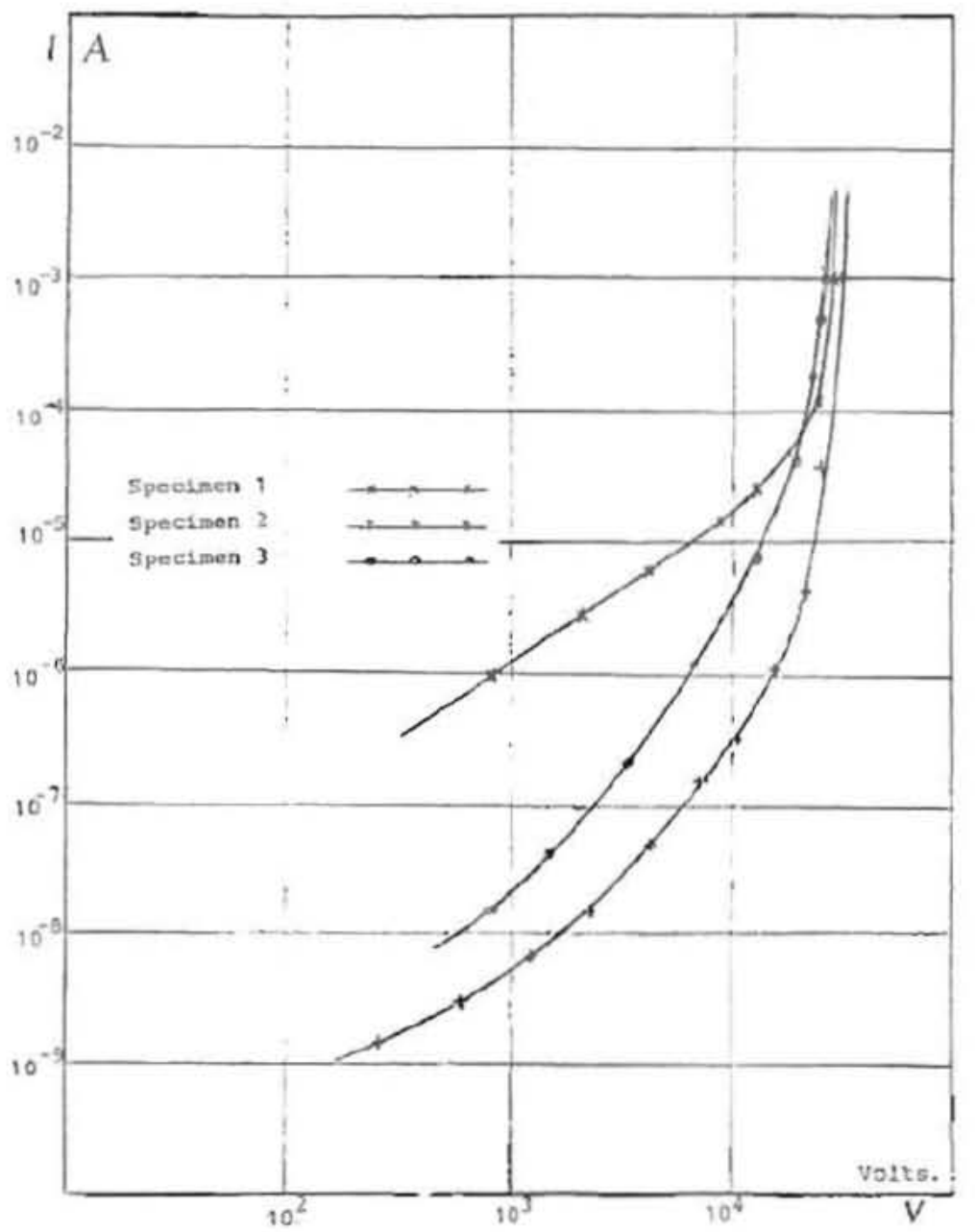

Fig. (5): Experimental results of I-V characteritic of non lineax films.

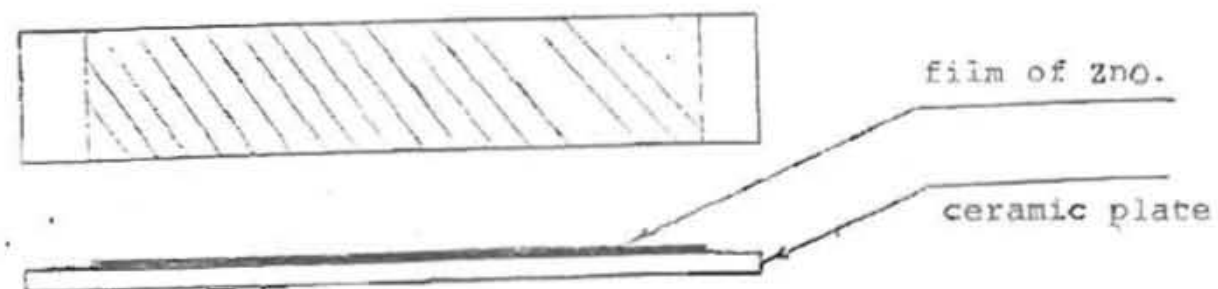

Fig. (6): Specimen of non linear fllm on the surface of ceramic. 
Table 121 gives the variations of $I_{d}$ and $t_{t}$ which are cajcwlated oy the equations given in wection $V$ for the two apocimons.

Table (2): Vartation of $I_{d} / t_{5}$

\begin{tabular}{|c|c|c|c|c|c|c|}
\hline \multirow{3}{*}{$\begin{array}{c}\text { Lenth } 0.5 \mathrm{~cm} \text { largo } 2 \mathrm{csi} \\
\mathrm{h}_{2}=7.1 \times 10^{-4} \mathrm{~b}_{3}=13.8 \\
v_{\mathrm{nn}}=2075 \text { volts. }\end{array}$} & $v_{\text {volts }}$ & 947 & 1021 & 1146 & $\{188\}$ & 2075 \\
\hline & ${ }^{1} \mathrm{~d}$ & $2 \times 10^{7}$ & $1 \times 10^{-1}$ & $5 \times 10^{-5}$ & $1 \times 10^{2}$ & $4 x+0^{3}$ \\
\hline & ${ }^{\mathrm{T}} \mathrm{s} \quad \mathrm{A}$ & $9.4 \times 10^{-9}$ & $2.3 \times 10^{7}$ & $0.1 \times 10^{7}$ & $3.2510^{4}$ & $\because \operatorname{art}$ \\
\hline \multirow{3}{*}{ 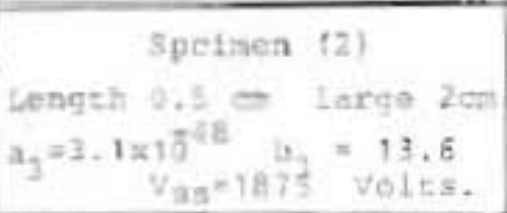 } & volt & 947 & 1021 & 1146 & toes & 2075 \\
\hline & Id & $2 \times 15^{-1}$ & $1 \times 10^{-1}$ & $5 x 10^{-2}$ & $1 \times 16^{2}$ & $0 \times 10^{-3}$ \\
\hline & $\mathrm{t}_{\mathrm{s}}$ & $9.3 \times 10$ & 2. $6 \times 10$ ? & $7.25 \times 10$ & $1,07 \times 16$ & $4 x: 0^{-3}$ \\
\hline
\end{tabular}

It has been found thet, if the voltage actoss the dry sone increases dise to the poliution on the insulator surface which choked tho eloctrid fiold across che dry zone; the current : increases accordisgly deponding on the voltage of non linear Zilm coacing the znsulator surface. This increase of durront Wall diminish the discharge across this dry zone.

Reforlay to the provious results, the chosce of the cbaractertstica of non Ilnear file la very important becaune the andrp increase of current $I_{g}$ deponds on the value of throshold voltace $Y_{\text {gs }}$ which deponda on the length of dry zone.

VII. CONCLUSIONS

The electrical charhcteristics of non-1ineas conductiv in intm have boun atudied to inveatigate the role of nor-1inoor fila whith coats the surface of H.V Lnsulators.

The lntluence of the lerith of non 11 near $f t 1$ m has been artudied and the equacionw for computing the tlashoret woltage have been doduced.

1t has been found that, the characcerintscs of non lineat tile, not only increases the flashover voltaye, but alad iteinstares the surface dirachoxye itaelf.

\section{VIIi. REFEAERCES}

(1) W. G. ROBtksok.

"Devalopments in porcelain insulators".

"Puviers of currently available Lnsulators for avertadad

lines and olecerica! equipment".

Aullera Ltd Electrical Review, October, 1972.

(2) S. FLASt; $c$. HURAUX; and $x$. TzzULARAB.

"Flashovor voltago on polluted insulating surface coated with a glightly conductive film".

IEEE Ifternational Symposium on $\bar{E}-1$ Montreal, Canada, June, 11-13, 19A4, 
[3] M. HASSANZADEH.

"Elaboration et caracterisation de varistance a base d'xoyde de zinc en couche epaisse".

These 3 émo cycle présontée a Université paul Sabalier, 1984.

[4] J. BERNASCONI, S. STRASSLER; B. KNECHT, H.P. KEEIN; and A. MENTA.

"Zlnc oxide based varietors: A possible mechanisw". Solid state communication Vo1. 21 No. 9, 1977.

(5) A.M. RAHAL; and C. HURAUX.

"Plashover mechanisa of high voltage insulators".

IEEE. Trans. PAS Vol. PAS-98 No. 5, 1979.

[6] M. IZZULARAB; and C. HURAUX.

"Study of proposed electrical models for contaminated surface on high voltage insulators".

Tenth International congresa. AIN SHAMS University EGYPT, 30 March: 4 April, 1985.

(7) [1. IZZULARAB.

"Colculation of HVDC flashover on the surface of conductive 1ce", 21 st University power Engineering conference UPEC'86, Imperial College London, ए.K. 15-17, Apz11, 1986.

(8) M.ALLIOUCHENE, C. HURAUX; and M. IZZULARAB,

"Calculation of the flashover voltage on a polluted insuatof surface using a bilayer model" .

IEEE conference on Electrical Insulation and Dielectric

phenomena Clayment (De). U.S.A October, 21-25, 1984.

[9] ALIOUCHENE,

"Contournement eléctrique de surface isolantes po:lutées: Modéle 3icouche A resistance non linéarire".

These de Dr. Ing. no 356, Prcsentee a INPT, 1985. 